\title{
The Neglected Cornerstone of Sustainable Development: Differential Treatment and Equity in The Climate Change Regime
}

\author{
Shawkat Alam \\ Professor, Department of Law, Macquarie University, Australia
}

\section{INTRODUCTION}

Sustainable development is neither coherent in its definition, nor in its status as a principle of international law. However, it has a well-established foundation in equity, which in this context refers to the equal distribution of resources amongst States. The principle of equity in sustainable development ensures that the three pillars of sustainable development are progressed. These are social, economic and environmental development. The Brundtland Report titled 'Our Common Future', places intergenerational and intragenerational equity at the forefront of sustainable development in its definition of: 'development that meets the needs of the present, without compromising the ability of future generations to meet their own needs'. However, the serious socio-economic asymmetry in resource access and use between the North and the South demonstrates that intragenerational equity, being fairness in the utilisation of resources among human members of present generations, is not adequately applied in international agreements, and has in fact been neglected. Notwithstanding the fact that intragenerational equity is integral to achieving sustainable development, it is merely implied in existing instruments and consequently there is little guidance on how it should be applied and the resultant obligations that it imposes on States. This has subsequently led to antipathy by the North in rigorously applying intragenerational equity to sustainable development. As a result, despite the many concluded international instruments, the goal of sustainable development is far from being achieved.

Sustainable development is a responsibility that is shared, albeit to a varying degree, between the North and the South. This is consistent with the principle of common but differentiated responsibilities (CBDR). This principle is essential in the realisation of sustainable development as it places differential responsibilities upon States to address both environmental and socio-economic inequities. More specifically, CBDR dictates that responsibility should be shared according to the resources States command and the pressures their societies place on the environment. Agreements such as the United Nations Convention on the Law of the Sea (UNCLOS), Convention on Biological Diversity (CBD), and the United Nations Framework Convention on Climate Change (UNFCCC) which provide for technology transfer from the North to the South are underutilised and in practice, less favourable for developing country parties. Consequently, there appears to be a dynamic of all take and no give between the North and the South, and a clear demonstration of the operation of reverse CBDR at the 
expense of the common goal of sustainable development.

International law and policy-making bodies may have embraced principles of sustainable development, however it is often argued that the newly emerging laws are lacking sufficient procedural detail about how to manage the implementation, development and enforcement of laws, regulations and international agreements, as they conceptually emerge relating to sustainable development.

Sustainable development principles are on the agenda in the UN legal system, in the minds of the Courts and form part of the claims brought before the legal system by state and individual claimants in conjunction with broader legal claims under human rights, trade and other legal banners. Indeed, sustainable development is not a standalone concept requiring its own special regime for enforcement or compliance monitoring. The appropriate systems are already in place, and it should be considered how this system can be fully exploited for the achievement of sustainable development goals.

Against this setting, this article firstly conducts an analysis of the relationship between sustainable development and the principle of CBDR. This article analyses the status of the CBDR principle in international law, followed by an examination of the ongoing tension between developed and developing countries regarding the meaning and operation of the CBDR principle. In the subsequent parts, this article then examines the extent to which the CBDR principle is reflected within provisions for adaptation finance and technology transfer and addresses the implications the operation of such provisions have on the achievement of sustainable development. It will be concluded that while sustainable development is a well-established concept in international law, the neglect of intragenerational equity and CBDR due to a lack of will from developed countries has resulted in a significant failure of sustainable development implementation.

\section{SUSTAINABLE DEVELOPMENT AND THE UNDERPINNINGS OF CBDR}

\section{A. CBDR and Sustainable Development}

The inception of sustainable development is considered to have occurred at the UN Stockholm Conference on the Human Environment. At Stockholm, the conflicts between the environment and development were first acknowledged. Further, in the 1980 World Conservation Strategy of the IUCN, which argued for conservation as a means to assist development and specifically for the sustainable development of species, ecosystems and resources. ${ }^{1}$

Nonetheless, the term sustainable development rose to the fore internationally in 1987

Kates Robert, Thomas Parris and Anthony Leiserowitz, 'What is Sustainable Development? Goals, Indicators, Values, and Practice' (2005) 47(3) Environment: Science and Policy for Sustainable Development 8; Tom Edwards, 'Sustainable Development' (2009) Briefing Paper No 4/09, Parliamentary Library, New South Wales, 3.

Page $\mid 18$ 
with the release of the World Commission on Environment and Development's Our Common Future report, ${ }^{2}$ also commonly referred to at the 'Brundtland Report' attributed to the fact it was authored by the committee chair, Gro Harlem Brundtland.

The Brundtland Report is acknowledged as providing the first official statement on sustainable development, although similar concepts had been propounded by various others in the decades prior. The Report articulated the core goals and principles associated with the early conception of sustainable development and sought to mandate that the world respond to the pervasive economic, social and environmental challenges that were apparent at the time the report was released. Critically, the Brundtland Report is credited with articulating the most widely accepted definition of sustainable development, which is:

'development that meets the needs of the present without compromising the ability of future generations to meet their own needs'.

This definition aligns with the view propounded in the Brundtland Report that 'humanity has the ability to make development sustainable; to ensure that it meets the needs of the present without compromising the ability of future generations to meet their own needs'. ${ }^{4}$ The view of the World Commission on Environment and Development was that the world could no longer feign ignorance in regard to the detrimental impacts of unsustainability on the environment and society. For this reason, the WCED sought to ensure that sustainable development remain a prominent element of economic dialogue into the future.

The concept of sustainable development was endorsed by various governments and political leaders around the world, subsequent to the WCED. This followed the WCED's identification of political commitment as critical to the sustainable development enterprise; indeed, as the report stated, 'in the final analysis, sustainable development must rest on political will', since the 'bodies whose policy actions degrade the environment' need to be made 'responsible... to prevent that degradation'.5 As a meta-policy, sustainable development provided the overarching normative and political architecture of sustainability, the responsibility was left with the respective global governments to facilitate it. ${ }^{6}$

The concept of sustainable development was elaborated upon through various documents and legal instruments agreed to at the 1992 Earth Summit held in Rio de Janeiro, Brazil (the United Nations Conference on the Environment and Development or UNCED). Five key documents were signed at the Earth Summit; the Rio Declaration on Environment and Development, Agenda 21, the Convention on Biological

2 Giorel Curran and Robyn Hollander, '25 Years of Ecological Sustainable Development in Australia: Paradigm Shift or Business as Usual?' (2015) 22(1) Australian Journal of Environmental Management $2,2$.

3 World Commission on Environment and Development, Our Common Future (Oxford University Press 1990) 392.

Ibid.

5 Ibid 17.

6 Giorel Curran and Robyn Hollander (n 2) 2. 
Diversity, the United Nations Framework Convention on Climate Change and the Statement of Forest Principles. As instruments of international law, state sovereignty precludes these documents from being legally binding. Nonetheless, the principles they espoused are highly relevant to the concept of sustainable development as it currently exists. In particular, the Rio Declaration enunciated the key principles of sustainability, including the principle of integration, the precautionary principle, the principle of intergenerational equity and the polluter pays principle.

\section{B. CBDR and its Convergence with Intragenerational Equity}

The CBDR principle is regarded as a principle of sustainable development. ${ }^{7}$ In essence, the dimensions of sustainable development are very much present in the concept of CBDR and vice versa. For instance, both the concept of sustainable development and CBDR prioritises needs among the economic, social and environmental spheres. CBDR assists States to proceed towards sustainable development that comprises all three aspects of economic, social and environmental sustainability. ${ }^{8}$ The CBDR principle shares an important feature of sustainable development where its constituent elements are very much interdependent as the relationship between poverty, environmental degradation and economic development. ${ }^{9}$

The crucial point of the definition of sustainable development established by the Brundtland Report is its focus on 'equity'. In this context it refers to meeting the needs of all people whether rich or poor and whether living present or in the future. On equity between generations, the Brundtland Report emphasises both intergenerational and intragenerational equity. According to the Declaration on the Responsibilities of the Present Generations towards Future Generations (UNESCO, 1997), present generations ought to be careful to utilize natural resources fairly and have a responsibility to leave future generations an earth which is not irrevocably damaged by human activity (Article 4). Apart from human activity, economic activities of countries to meet existing needs should not exhaust the environment so much that people will not be capable of meeting their needs in the future.

Intragenerational equity, on the other hand, refers to fairness in utilisation of resources among human members of present generations, both domestically and globally. ${ }^{10}$ Intragenerational equity is intimately related to the developing-developed State

7 The International Law Association's New Delhi Declaration of Principles of International Law Relating to Sustainable Development has included CBDR as one of the leading principles of sustainable development law: 'ILA New Delhi Declaration of Principles of International Law Relating to Sustainable Development' UN World Summit on Sustainable Development (Johannesburg 26 August - 4 September 2002) (6 April 2002) UN Doc A/CONF.199/8.

8 Tuula Kolari, 'The Principle of Common but Differentiates Responsibilities as Contributing to Sustainable Development through Multilateral Environmental Agreements' in Hans Christian Bugge and Christina Voigt (eds), Sustainable Development in International and National Law (Europa Law Publishing 2008) 251, 259

9 Ibid.

10 G F Maggio, 'Inter/intra-generational Equity: Current Applications under International Law for Promoting the Sustainable Development of Natural Resources' (1997) 4 Buffalo Environmental Law Journal 161, 162.

Page $\mid 20$ 
controversy. Intragenerational equity dictates that developed countries, having ownership over the bulk of the resources and technology, and wealth accrued through exploitation of those resources, bears the burden of ensuring that equitable distribution occurs. The principle of intragenerational equity takes more concrete shape in the CBDR principle which states that responsibility should be shared according to the resources States command and the pressures their societies place on the environment. ${ }^{11}$

Intragenerational equity is far from being an enforceable right in law. As such, vulnerable countries which have the greatest need to enforce the right to intragenerational equity have no reprieve for the inequalities faced. The Brundtland Report explicitly contextualises environmental sustainability as an issue of, not only intergenerational but also intragenerational equity (WCED, 6, 11, 43, 52). ${ }^{12}$ The Brundtland Report emphasised that intergenerational equity is logically extendible to equity within each generation. ${ }^{13}$ John Ntambirweki argues:

It is presumptuous to speak of intergenerational equity when there is no intragenerational equity. There could be no greater disservice to the human species than the passing of present intragenerational inequities to future generations. This disservice lies not in the morality of the deed, but rather in the fact that the earth's single environment is crucial to the survival of humanity as a whole. Without righting the wrongs of today, and extinguishing present inequalities, there will remain nothing to bequeath to the future. ${ }^{14}$

Okereke pertinently observed that 'the struggle to secure intragenerational equity in the context of global environmental regimes can be conceived as a counter hegemonic project driven mainly by developing countries'. ${ }^{15}$

\section{SITUATING CBDR AS A BRIDGE ACROSS THE NORTH-SOUTH DIVIDE}

\section{A. Whose Law? The North-South Divide}

There has been increasing recognition of the CBDR principle in international environmental law. It apprehends the notion of differential treatment towards developing countries, ${ }^{16}$ and has developed from the recognition that the 'special needs of developing countries must be taken into account in the development, application and interpretation of rules of international environmental law'. ${ }^{17}$ Principle 7 of the Rio

11 'Report of the United Nations Conference on Environment and Development' (12 August 1992) UN Doc A/CONF.151/26, vol 1 annex I ('The Rio Declaration on Environment and Development') principle 7.

12 Chukwumerije Okereke, 'Global Environmental Sustainability: Intragenerational Equity and Conceptions of Justice in Multilateral Environmental Regimes' (2006) 37 Geoforum 725, 726.

13 Lavanya Rajamani, Differential Treatment in International Environmental Law (Oxford University Press 2006) 153.

14 John Ntambirweki, 'The Developing Countries in the Evolution of an International Environmental Law' (1995) 14 Hastings International and Comparative Law Review 905, 924.

15 Chukwumerije Okereke (n 12) 735.

16 Lavanya Rajamani (n 13) 129.

17 Philippe Sands and Jacqueline Peel, Principles of International Environmental Law (4th edn, Cambridge University Press 2018) 244. 
Declaration states that:

In view of the different contributions to global environmental degradation, States have common but differentiated responsibilities. The developed countries acknowledge the responsibility that they bear in the international pursuit to sustainable development in view of the pressures their societies place on the global environment and of the technologies and financial resources they command.

It is unequivocally accepted that two predominant thoughts emanate from Principle 7 of the Rio Declaration: the existence of a 'common responsibility' of States for the protection of environment and the more contentious aspect of 'differentiated responsibility' of States according to their contribution to environmental harm and the capacity to address it. ${ }^{18}$ The notion of 'common responsibility' derives from the notions of 'common concerns', 'common heritage of humankind' and the 'province of humankind'. ${ }^{19}$ The common responsibility in the CBDR principle signifies the principle of cooperation among States to prevent and respond to transboundary pollution. ${ }^{20}$ Yamin and Depledge emphasise the common concern aspect underlying CBDR as opposed to differential treatment more generally. ${ }^{21}$ Yamin and Depledge state that the principle of CBDR, 'in essence refers to the fact that certain problems affect and are affected by all nations in common... and that the resulting 'responsibilities' ought to be differentiated because not all nations should contribute equally to alleviate the problem. ${ }^{22}$ In addition to recognising the broad distinctions between states on the basis of their responsibility for causing environmental harm, this fundamental distinction between the North and South acknowledges that people are affected by environmental degradation to varying degrees; the poor most severely. There is, therefore, a need to strengthen the capacity of the poor and their representatives to defend their environmental rights to ensure weaker sections of society are not harshly prejudiced by environmental degradation and instead enjoy their right to live in a social and physical environment that respects and promotes their dignity.

The Rio Declaration was a key moment in the history of sustainable development as it constituted a universal acceptance by states of their rights and responsibilities in achieving sustainable development. It is a document that reflects the North-South interests more distinctly and even-handedly than has been seen before, or, indeed, since. Principle 3 of the Rio Declaration recognises the "right to development" of states as sovereign. However, sustainable development poses a limit on this sovereignty by requiring that the right to development be subjected to the caveat that developmental

18 Philippe Sands and Jacqueline Peel (n 17) 244; Lavanya Rajamani (n 13) 133; Christopher D. Stone, 'Common but Differentiates Responsibilities in International Law' (2004) 98(2) American Journal of International Law 276, 276-7.

19 Lavanya Rajamani (n 13) 134.

20 Ibid.

21 Farhana Yamin and Joanna Depledge, The International Climate Change Regime: A Guide to Rules, Institutions and Procedures (Cambridge University Press 2004) 69.

22 Ibid.

Page $\mid 22$ 
and environmental needs of present and future generations are not compromised, though developing countries insist that their rights to development should not be sacrificed for the protection of the environment. The argument is that developed countries are developed precisely because of their earlier unsustainable practices of natural resource exploitation prior to the genesis of modern environmental consciousness and the growth of supra-governmental regulation coming into being, attendant upon this new awareness. It is argued that it is only fair that developing countries should not be required to suffer restrictions to their right to development to the same extent as those countries have already enjoyed the fruits of uninhibited development without environmental regulation.

In this way, Principle 7 is important in providing that States have a common but differentiated responsibility to pursue sustainable development. This is a key concession for developed states, acknowledging their responsibility in the pursuit of sustainable development, considering the impacts of their societies on the global environment, the technologies they employ and the financial resources they have to spend. By making this concession, developed countries accepted in Principle 7 the obligation to share knowledge, transfer technologies and financially assist developing countries to achieve the sustainable development goals. What was essentially agreed to in this Principle was the need for cooperation in capacity building so that sustainable development goals could be delivered. Similarly, the Johannesburg Summit (2002) witnessed high level and diverse participation. The 'holistic approach' taken, through investments and capacity building, was a step forward to enable effective implementation of sustainable development. The Millennium Declaration consolidated previous international agreements and ushered the way forward.

In practical terms, the application of the CBDR principle has certain essential consequences. ${ }^{23}$ First, it requires all concerned states to take part in international response measures aimed at tackling environmental problems. Second, it leads to the adoption and implementation of environmental standards which impose different commitments for different states. Overall, this principle is intended to promote fairness and equity. Although the CBDR principle has remained at the centre of the sustainable development agenda, ${ }^{24}$ the true nature of its application remains uncertain and sometimes controversial. Promises of aid and technology transfer are unfulfilled or regressive. Soft laws and consensus-based statements are difficult to enforce when international institutions fail to offer clear direction on sustainable development. Without embracing equity as the central tenant of sustainable development, there can be no wholesale adoption of the SDGs across the North and the South. At the same time, there are diverse opinions and priorities not only between the Global South and the Global North but also within the Global South.

23 Ashfaq Khalfan, 'The Principle of Common but Differentiated Responsibilities: Origins and Scope' (Paper presented to the World Summit on Sustainable Development Johannesburg, South Africa, 26 August 2002) <http://cisdl.org/public/docs/news/brief_common.pdf > accessed 29 January 2021.

24 UNGA 'The Future We Want' UNGA Res 66/288 (27 July 2012) UN Doc A/RES/66/288; UNGA 'Transforming our World: The 2030 Agenda for Sustainable Development', UNGA Res 70/1 (25 September 2015) UN Doc A/RES/70/1. 


\section{B. Markers of Differentiation: Contribution, Capacity and Needs}

There are a number of approaches to the operation of differential treatment. The arguments fall under three different headings. contribution, capacity and needs. ${ }^{25}$ With regard to contribution there is a 'striking asymmetry' between developed and developing countries concerning resource exploitation and related environmental damage. ${ }^{26}$ The capacity criterion justifies differential treatment on the grounds that developed states have a greater current ability to absorb the consequences of environmental degradation and should therefore shoulder a greater burden in terms of obligations. As with 'contribution', this idea is upheld in legal instruments in the context of discussing the general commitments of nations. The United Nations Environment Programme (UNEP) has underlined the central importance of 'development', stating that the emphasis on respective capabilities is related to different levels of development. ${ }^{27}$ Differentiation with regard to capacity does not simply translate into greater expenditure on environmental protection measures. Generally, developed countries enjoy more mature economies that can absorb such expenditure and do not have to balance dual and often conflicting goals such as environmental protection and poverty eradication. The preoccupation amongst developing countries to alleviating poverty can be viewed as impacting upon the capacity to ameliorate environmental degradation but this resonates more strongly with the third justification for differential treatment - 'needs.' Differentiation in this way would ensure that those deserving of assistance receive it and those not deserving do not. Differentiation on the basis of needs is particularly relevant to this article and is explicitly endorsed in the preamble to the UNFCCC that recognizes that 'sustainable growth' and the 'eradication of growth' are the legitimate priorities of developing countries. $^{28}$

Rajamani identifies three ways in which differential treatment operates in the context of international environmental legal instruments:

- Provisions that differentiate between developed and developing countries with regard to the central commitments of the particular agreement;

- Provisions that differentiate between developed and developing countries with respect to implementation, for example delayed compliance and reporting schedules, permission to adopt subsequent base years and soft approaches to non-compliance; and

- Provisions that grant assistance, inter alia, financial and technological. ${ }^{29}$

${ }^{25}$ Lavanya Rajamani (n 13).

26 Andrew Hurrell and Benedict Kingsbury, 'An Introduction' in Andrew Hurrell and Benedict Kingsbury (eds), The International Politics of the Environment (Clarendon Press 1992) 39.

27 United Nations Environment Programme, Final Report of the Expert Group Workshop on International Environmental Law aiming at Sustainable Development (UNEP, 1996) para 43(a).

28 United Nations Framework Convention on Climate Change (adopted 9 May 1992, entered into force 24 March 1994) 1771 UNTS 107 (UNFCCC) Preamble.

29 Lavanya Rajamani (n 13) 93.

Page $\mid 24$ 
In practice, most international environmental instruments contain provisions that assist developing countries to fulfil their obligations in recognition of the fact that they face significant economic and technical capacity constraints that enhance their existing vulnerabilities to the impacts of climate change. The provision of financial resources is often described as being 'new and additional in order to meet 'full incremental costs' of compliance. ${ }^{30}$ Similarly, numerous treaties and soft law agreements have recognised that the provision of technology transfer to developing countries is necessary for climate change mitigation and adaptation, and in turn sustainable development. ${ }^{31}$

Yet this raises a central dilemma that plagues the operation of CBDR. As Rajamani outlines:

Both at the negotiations, and in the scholarly literature, there are at least two incompatible views on its [CBDR] content. One, that the CBDR principle is 'based on the differences that exist with regard to the level of economic development.' And the other, that the CBDR principle is based on 'differing contributions to global environmental degradation and not in different levels of development. ${ }^{32}$

\section{Historical Contribution to Climate Change}

Developed countries' excessive use of environmental resources has rendered the condition of the global environment deplorable. Small Island States and the African dry regions that have emitted the least Greenhouse Gases (GHGs) are the most vulnerable to the adverse impacts of climate change. Some of these countries and regions are likely to lose their territories to climate change, though their contribution in bringing on this state of play is meagre. This presents a clear case of historical injustice from which a valid claim for recognition, compensation, and correction could arise. ${ }^{33}$ Indeed, such obligations have been reflected in the Beijing Ministerial Declaration on Environment and Development, which declared that:

While the protection of the environment is in the common interests of the international community, the developed countries bear the main responsibility for the degradation of the global environment. Ever since the industrial revolution, the developed countries have over-exploited the world's natural resources through unsustainable patterns of production and consumption, causing damage to the global environment, to the detriment of the developing countries. $^{34}$

30 Ibid 108.

31 Intergovernmental Panel on Climate Change, Methodological and Technological Issues in Technology Transfer (Special Report of IPCC Working Group III, 2000) 16, 87. See, eg, Kyoto Protocol to the United Nations Framework Convention on Climate Change (adopted 11 December 1997) 2303 UNTS 162 (Kyoto Protocol) 3.14; Paris Agreement (adopted 12 December 2015, entered into force 4 November 2016) UNTS No 54113 (Paris Agreement) art 10.2.

32 Lavanya Rajamani, 'From Berlin to Bali and Beyond: Killing Kyoto Softly?' (2008) 57 International and Comparative Law Quarterly 909, 911.

33 Lavanya Rajamani (n 13) 139.

34 UNCED, Beijing Ministerial Declaration on Environment and Development (19 June 1991) UN Doc 
Since the appearance of climate change on the international political agenda, developing countries strongly argued for turning CBDR into practice through the concept of historical responsibility. ${ }^{35}$ The Group of 77 (G-77) expressed at the onset of the UNFCCC negotiations:

Since developed countries account for the bulk of the production and consumption of environmentally damaging substances, they should bear the main responsibility in the search for long-term remedies for global environment protection and should make the major contribution to international efforts to reduce the consumption of such substances. ${ }^{36}$

Historical responsibility was prioritised in the submission by Brazil (known as the 'Brazilian Proposal') prior to the Kyoto Protocol suggesting that Annex 1 burdens should be based on the relative levels of past emissions and their effects as manifested in the present climate. ${ }^{37}$ On the other hand, most developed countries, particularly the United States, take position against recognising any kind of historical responsibility and emphasise that the leadership role of developed countries is based on their wealth, technical expertise and capabilities. ${ }^{38}$ Also, it has been argued, drawing upon the absence of a clear provision on historical responsibility in Article 3 of the UNFCCC, that UNFCCC does not recognise historical responsibilities of developed countries. However, as noted above, Article 3 must be read along with the Preamble of the UNFCCC, which does show a recognition of the historical contribution of developed countries.

Insofar as the present generations of developed countries are benefitting from the actions of the past generations in borrowing from the earth's assimilative capacity, they must be held morally responsible for the consequential liabilities. ${ }^{39}$ Rajamani argues to hold developed countries legally responsible for their historical wrongs by applying the principle of respect for the sovereignty of other States. She argues

If the international community has any sympathy with Australia's claim that its sovereignty was adversely affected by the radioactive fallout from French nuclear tests in the Pacific ${ }^{40}$ surely it must also recognise the legitimacy of claims from Tuvalu and other small island states that their sovereignty is fundamentally breached by GHG emissions from industrial countries. ... in so

A/CONF.151.PC/85 annex, para 7.

35 Mathias Friman and Bjorn-Ola Linner, 'Technology Obscuring Equity: Historical Responsibility in UNFCCC Negotiations' (2009) 8(4) Climate Policy 339, 340

${ }^{36}$ G-77, 'Caracas Declaration of the Ministers of Foreign Affairs of the Group of 77 on the Occasion of the twenty-Fifth Anniversary of the Group' (1989) <https://www.g77.org/doc/Caracas\%20 Declaration.html> accessed 28 January 2021.

37 UNFCCC, 'Proposed Elements of a Protocol to UNFCCC, presented by brazil in Response to the Berlin Mandate' (1997) FCCC/AGBM/1997/MISC.1/Add.3.

38 Duncan French, 'Developing States and International Environmental Law: The Importance of Differentiated Responsibilities' (2000) 49 International and Comparative Law Quarterly 35, 37.

39 Lavanya Rajamani (n 13) 140; Henry Shue, 'Global Environment and International Inequality' (1999) 75(3) International Affairs 531, 536.

40 Application by Australia Instituting Proceedings, Nuclear Tests (Australia v France) (1973) ICJ Proceedings, Nuclear Tests, Vol I, 14.

Page $\mid 26$ 
far as it constitutes a historical wrong it could give rise to a valid claim for historical responsibility. ${ }^{41}$

Rajamani strongly critiqued the dubious actions of developed countries whereby they deny any historical responsibility but argue for recognition of entitlements based on historical GHG emissions. ${ }^{42}$ This prevails in the current structure of the UNFCCC which accepts historical patterns of emissions as the basis for allocating mitigation commitments between developed countries. ${ }^{43}$ Rajamani argued that '[i]f we are to accept historical entitlements... then surely we must also accept the inevitable truckle with historical wrongs'. ${ }^{44}$

The key underlying justification for a strong, legally mandated, international framework of adaptation is that developed countries are directly responsible for the impacts of climate change. Hence, logically, developed countries must bear responsibility for funding the costs of adaptation. Any commitments made by developed countries must also be built on an acceptance of this legal responsibility rather than assuming adaptation as a charity to the poor and vulnerable. ${ }^{45}$ The aim of future negotiations should aim at building on this legal foundation in order to strengthen the funding and technological support that is available to vulnerable countries. $^{46}$

Furthermore, the Commission on Sustainable Development affirms that developed countries bear a special responsibility in the context of CBDR, because the major cause of the continued deterioration of the global environment is the unsustainable pattern of consumption and production in industrialised countries. ${ }^{47}$ Evidence of developed nations' disproportionate environmental impacts was assessed by the New Economics Foundation in their report titled 'Growth Isn't Working'. The report found that:

For everyone on Earth to live at the current European average level of consumption, we would need more than double the bio capacity actually available - the equivalent of 2.1 planet Earths - to sustain us. If everyone consumed at the US rate, we would require nearly 5...Europe's levels of consumption amount to more than double its own domestic bio capacity, meaning that European lifestyles can only be sustained by depending on the natural resources and environmental services of other nations. ${ }^{48}$

\footnotetext{
Lavanya Rajamani (n 13) 142.

Ibid.

43 Benito Muller, Justice in Global Warming Negotiation: How to Obtain a Procedurally Fair Compromise (Oxford Institute for Energy Studies 1998) 7.

44 Lavanya Rajamani (n 13) 143-4.

45 Will McGoldrick, 'Financing Adaptation in Pacific Island Countries: Prospects for the Post-2012 Climate Change Regime' (2007) 14 Australian International Law Journal 45, 63.

46 Ibid.

47 ECOSOC, 'Commission on Sustainable Development Report of the Third Session' (11-28 April 1995) E/1995/32-E/CN.17/1995/36, para 31.

48 New Economics Foundation, Growth Isn't Working; The unbalanced distribution of benefits and costs from economic growth (2006) 3 <http://www.neweconomics.org/gen/uploads/hrfu5w555mzd3 f55m2vqwty502022006112929.pdf> accessed 27 January 2021.
} 
Accordingly, the consumption levels of developed countries would not be sustainable if such levels were evident across the globe; thus development must be sustainable and pursued in light of the principle of CBDR. The report further noted that:

...the benefits of economic growth accrue only very weakly to the poorest members of the global community. The costs of growth, however, for example in the consequences of global warming, fall disproportionately on the poorest. $^{49}$

These findings provide clear evidence that the majority of the burden to ensure sustainable development and differentiated responsibilities should fall on the developed states. The Hague Declaration 1989, the General Assembly Resolution 44/228, 1989, and the Beijing Declaration 1991 highlight the fact that industrialised countries have a disproportionate impact on the environment and therefore special obligations to take response measures. GA Resolution 44/228 drew attention to the fact that 'the major cause of the continuing deterioration of the global environment is the unsustainable pattern of production and consumption, particularly in industrialised countries' and noted that 'the responsibility for continuing, reducing and eliminating global environmental damage must be borne by the countries causing such damage, must be in relation to the damage caused and must be in accordance with their respective capabilities and responsibilities'. ${ }^{50}$

As Rajamani argues, States have a customary international law obligation to 'ensure that activities within their jurisdiction and control respect the environment of other States or of areas beyond national control'. ${ }^{51}$ The ICJ in Legality of the Threat or Use of Nuclear Weapons, holds that this notion is 'part of the corpus of international law relating to the environment'. ${ }^{52}$ The ICJ also noted in the Corfu Channel Case that it is a general and well-recognised principle that every State has an 'obligation not to allow knowingly its territory to be used contrary to the rights of other States' ${ }^{53}$ Drawing on these principles, Rajamani argues that international law recognises and holds States responsible for current contributions to environmental degradation. ${ }^{54}$

\section{Capacity to Take Remedial Measures}

Of particular interest is the debate regarding the second limb of CBDR; differentiated responsibility due to economic and technological capacity. Differentiation as a result of economic and technological capacity is not a new concept in international law. Differential demands appeared in the Treaty of Versailles (1919) in which the International Labour Organisation (ILO) recognised that 'differences of climate, habits and customs, of economic opportunity and industrial tradition, make strict uniformity

\footnotetext{
Ibid.

50 UNGA Res 44/228 (22 December 1989) UN Doc A/RES/44/228; Lavanya Rajamani (n 13) 131.

51 Lavanya Rajamani (n 13) 143-4,

52 Legality of the Threat or Use of Nuclear Weapons (Advisory Opinion) [1996] ICJ Rep 226, 241-2.

53 Corfu Channel Case (UK v Albania) [1949] ICJ Rep 3, 22.

54 Lavanya Rajamani (n 13) 144.
}

Page $\mid 28$ 
in the conditions of labour difficult of immediate attainment' ${ }^{55}$ In 1965, the Contracting Parties of the General Agreement on Tariffs and Trade (GATT) added provisions to encourage non-reciprocal trade concessions in favour of developing countries and even, in 1979, expressly enable 'differential and more favourable' tariff treatment. ${ }^{56}$ Simultaneously, in the late 1960s and the early 1970s developing countries called for the New International Economic Order (NIEO) to establish a legal regime of positive discrimination in favour of developing countries. ${ }^{57}$ Though the attempt failed in strong opposition from developed countries, this principle of differentiated responsibility is enshrined in international environmental instruments since the Stockholm Declaration ${ }^{58}$ and also found its place in many treaties. ${ }^{59}$

The United States has interpreted Principle 7 of the Rio Declaration to "acknowledge "the special leadership role of developed countries" due to their "wealth, technical expertise and capabilities". ${ }^{60}$ The United States' interpretative statement also emphasized that Principle 7, 'does not imply a recognition... of any international obligations...or any diminution in the responsibility of developing countries ${ }^{61}$ thus departing from the Principle 7's text, which clearly states the existence of common but differentiated responsibilities - including different roles for developing nations. During the negotiations of the UNFCCC, developed countries opposed any language pertaining to contribution to environmental degradation. ${ }^{62}$

The question of capacity has varying views. As Weiss notes, the positive correlation of capacity and environmental degradation is questionable, as India, Brazil and China

55 Constitution of the International Labour Organisation, June 28, 1919, art 427, 49 Stat. 2712, 2733-34, 225 Consol. T. S. $188,385$.

56 Differential and More Favourable Treatment Reciprocity and Fuller Participation of Developing Countries - Decision of 28 November 1979 L/4903 <https://www.wto.org/english/docs_e/legal_e/ enabling1979_e.htm> accessed 27 January 2021.

57 Lavanya Rajamani (n 13) 17.

58 Principle 12 of the Stockholm Declaration endorsed 'taking into account the circumstances and particular requirements of developing countries and any costs which may emanate from their incorporating environmental safeguards into their development planning and the need for making available to them, upon their request, additional international technical and financial assistance for this purpose'. Principle 6 of the Rio Declaration states: 'The special situation and needs of developing countries, particularly the least developed and those most environmentally vulnerable, shall be given priority'. Principle 7 of the Rio Declaration states that the CBDR principle also upholds the principle of differentiated responsibility.

59 See, eg, United Nations Convention on the Law of the Sea, (adopted 10 December 1982, entered into force 16 November 1994) 1833 UNTS 3 (UNCLOS) art 207; Vienna Convention on the Law of Treaties (adopted 22 May 1969, entered into force 27 January 1980) 1155 UNTS 331 (VCLT) art 2; UNFCCC (n 28) art 3(2).

Ibid.

62 Lavanya Rajamani (n 13) 137. Christopher D. Stone justified the action of the US in his observation: 'the sense of the Senate does not appear to oppose CBDR in principle ... many senators are agreeable to subjecting developing countries to less restrictive constraints ... as long as they make some commitments on paper': Christopher D. Stone (n 18) 280. 
may be major contributors to environmental damage, but their capacity for remedying the problem may not be able to match their contribution. ${ }^{63}$ It has also been criticised by Biniaz, who argues that the application of CBDR leads to laziness in the negotiating process of international agreements as developing countries assume its application and refuse to comply. ${ }^{64}$ It is argued that capacity should not be viewed as separate from the other limbs of CBDR and should be rigorously applied to all states, including developing states as their capacity increases. In the environmental regime, the CBDR principle is implemented through redistribution of resources. It is a significant means of differentiating between countries within international environmental agreements. Resource redistribution can mainly be realised by allocation of financial assistance, transfer of technology and capacity building. ${ }^{65}$ This article investigates financial assistance and at technology transfer in the following parts as examples of the application of the CBDR principle and its implications for sustainable development.

\section{OPERATION OF CBDR THROUGH CLIMATE CHANGE ADAPTATION FINANCE}

\section{A. Defining Adaptation Finance and its Emergence through the UNFCCC}

The IPCC defines climate change adaptation as an 'adjustment of natural or human systems in response to actual or expected climatic stimuli or their effects, which moderates harm or exploits beneficial opportunities'. ${ }^{66}$ A report of the LDC Expert Group states that adaptation involves reducing the impacts of climate change that are happening now and increasing resilience to future impacts, taking into account the urgent and immediate needs of developing countries that are particularly vulnerable. ${ }^{67}$ Adaptation can take the form of activities designed to enhance the adaptive capacity of the respective system, or actions that modify socio-economic and environmental systems to avoid or minimize the damage caused by climate change. Methods for achieving these include implementing new activities that are exclusively in response to climate change, or the modification of existing activities to make them more resilient to future climate change risks (i.e. 'climate-proofing'). ${ }^{68}$ Further, adaptive capacity refers to the potential or ability of a system (social, ecological, economic, or an

63 Edith Brown Weiss, 'The Rise and Fall of International Law' (2000) 69 Fordham Law Review 345, 368.

64 Susan Biniaz, 'Common But Differentiated Responsibilities in Perspective' (2002) 96 American Society of International Law Proceedings 359, 363.

65 Tuula Honkonen, The Principle of Common but Differentiated Responsibility in Post-2012 Climate Negotiations' (2009) 18(3) Review of European, Comparative and International Environmental Law $257,258$.

${ }^{66}$ Intergovernmental Panel on Climate Change (IPCC), Working Group 1 Contribution to the Fourth Assessment Report of the IPCC: The Physical Science Basis, Summary for Policy Makers (Cambridge University Press 2007) 869 < https://www.ipcc.ch/site/assets/uploads/2018/02/ar4-wg1-spm-1.pdf> accessed 28 January 2021.

67 LDC Expert Group, 'Best Practices and Lessons Learned in Addressing Adaptation in the Least Developed Countries through the National Adaptation Programme of Action Process' vol 1 (UNFCCC

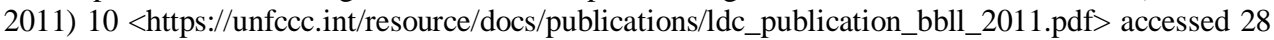
January 2021.

68 Ibid.

Page $\mid 30$ 
integrated system such as a region or community) to minimize the effects or impacts of climate change, or to maximize the benefit from the positive effects of climate change. ${ }^{69}$ Such broad definitions to help visualise climate change adaptation allow some degree of flexibility as our understanding of adaptation develops, however it can also lead to different expectations with funding implications. ${ }^{70}$

Adaptation finance is critical as many of the most vulnerable communities and individuals are among the world's poorest. ${ }^{71}$ Vulnerable countries must secure financial support in order to be able to anticipate and react to the adverse effects of climate change. ${ }^{72}$ As Article 8 of the Copenhagen Accord recognises:

Funding for adaptation will be prioritized for the most vulnerable developing countries, such as the least developed countries, small island developing States and Africa.

Adaptation finance has been operationalised through various international instruments. UNFCCC Article 3(1) places a duty to assist on the basis of the capability and provides a correspondence right to assistance for those with limited capability to deal with climate change. Furthermore, article 2 creates responsibilities to pursue the natural adaptation of ecosystems, thus implying that negative outcomes resulting from climate change can be avoided if stabilisation of GHG concentrations enables natural adaptation of ecosystems, food production and sustainable development. ${ }^{73}$

Under Article 4(1)(b) of the UNFCCC, all Parties are required to 'formulate implement, publish and regularly update ... measures to facilitate adequate adaptation to climate change'. Article 4(1)(e)-(f) commits the Parties to cooperate in adaptation planning and to incorporate climate change considerations into their economic, social and environmental policies so as to minimise adverse effects on public health, environmental quality and on mitigation and adaptation measures. In line with the principle of differentiated responsibilities and adaptive capabilities, Article 4(3) of the Convention also requires that developed countries provide "the agreed full incremental costs' incurred by developing countries in complying with their reporting obligations. Article 4(4) commits developed countries 'to assist developing country Parties that are particularly vulnerable to the adverse effects of climate change in meeting costs of adaptation to those adverse effects'. Article 4(8) requires that all countries 'give full consideration to what actions are necessary under the Convention, including actions related to funding, insurance and the transfer of technology, to meet the specific needs

69 LDC Expert Group, 'Step-by-Step Guide for Implementing National Adaptation Programmes of Action' (UNFCCC 2009) 3 <https://unfccc.int/resource/docs/publications/ldc_napa2009.pdf> accessed 28 January 2021.

70 Rosalind Cook, 'Legal Responses for Adaptation to Climate Change: The Role of the Principles of Equity and Common but Differentiated Responsibility' (MA Thesis, University of Utrecht, May 2010).

71 Intergovernmental Panel on Climate Change (IPCC) (n 66).

72 Nicola Peart, 'Dispute in Climate Change Adaptation Finance - Towards a Convergent Outcome for the COP-15' (2009) European Energy and Environmental Law Review 307, 308.

73 Jouni Paavola and W. Neil Adger, 'Fair Adaptation to Climate Change' (2006) 56 Ecological Economics 594, 598. 
and concern of developing country Parties arising from the adverse effects of climate change'.

To support these important commitments, Article 11 of the UNFCCC establishes a financial mechanism by setting forth it general characteristics and governance. Article 11 is to be read in conjunction with Article 21(3) which entrusts the Global Environment Facility (GEF) with the operation of the financial mechanism. The GEF is guided by COP decisions that decide upon programme priorities and eligibility requirements for funding - in conjunction with advice from the Subsidiary Body for Implementation (SBI) under the UNFCCC. This was further strengthened at COP 16 where the Green Climate Fund (GCF) was established and designated an operating entity of the financial mechanism under Article 11 of the Convention. ${ }^{74}$

Parties to the Convention also established specific funds, namely the Least Developed Country Fund (LDCF) and the Special Climate Change Fund (SCCF). The GEF Trust Fund historically lacked a formal operational procedure within its climate change focal area. The GEF is subject to certain criteria including securing global environmental benefits. Satisfying this criterion has proven to be a significant challenge as most adaptation projects generally only carry local benefits.

The SCCF and LDC Funds were created following COP 7, 2001 and continue to serve the Paris Agreement. These funds are supported through discretionary pledges from donors only. Further, funding hinges upon approval of the adaptation project from the donor nation and the preferences of developed countries might not accord with adaptation needs. Both the LDCF and SCCF are operated by the GEF. Additionally, the Adaptation Fund (AF) is a self-standing fund established under the Kyoto Protocol to finance concrete climate change adaptation projects and programs based on the needs, views and priorities of developing countries. This fund has also served the Paris Agreement since 1 January 2019 in accordance with decisions 13/CMA.1 and 1/CMP.14.

However, the central provision of the UNFCCC, article 4(4), remains ambiguous and provides no clear objective guidance on how developed countries can fulfil their obligations, or whether compliance is achieved at 'full incremental costs' or merely costs as agreed. ${ }^{75}$ Given the lack of clear guidance to achieve compliance, the climate change adaptation finance provisions of the UNFCCC fails to achieve the principles and objectives of CBDR and obligations that ensure that developed countries - which have the capacity to provide assistance - provide equitable relief given the context of historical contributions that developed countries have made to the existing climate crisis.

\section{B. The Paris Agreement}

The Paris Agreement is distinct from the UNFCCC and its Kyoto Protocol by

\footnotetext{
74 UNFCCC, 'Report of the Conference of the Parties' (15 March 2012) FCCC/CP/2011/9/Add.1, annex ('Governing Instrument for the Green Climate Fund')

75 Lavanya Rajamani (n 13).
}

Page $\mid 32$ 
emphasising the importance of climate change adaptation. ${ }^{76}$ This goal is intended to contribute to sustainable development by 'enhancing adaptive capacity, strengthening resilience and reducing vulnerability to climate change' ${ }^{77}$ Further, while the Paris Agreement notes that 'Parties should strengthen their cooperation on enhancing action on adaptation' ${ }^{78}$ it also emphasises 'the importance of taking into account the needs of developing country Parties'. ${ }^{79}$ This recognition of the need for differential treatment for developing countries on the basis of their particular vulnerabilities to the adverse effects of climate change and need for support on adaptation efforts, is reminiscent of the capacity limb of CBDR.

Despite this, the Paris Agreement's provisions for climate change adaptation finance are limited, inhibiting the potential benefits of CBDR for achieving sustainable development. While Article 9 of the Agreement requires developed countries to 'provide financial resources to assist developing country Parties with respect to both mitigation and adaptation', ${ }^{80}$ it only imposes a general obligation for the provision of 'continuous and enhanced international support' to developing countries. ${ }^{81}$ Developed countries continue to enjoy a large degree of autonomy when determining their adaptation finance commitments, undermining the principle of CBDR. For this reason, the Paris Agreement has failed to address the continuing disagreements between the North and the South, further entrenching the 'dividing lines between developing and developed countries' ${ }^{82}$

\section{OPERATION OF CBDR THROUGH TECHNOLOGY TRANSFER PROVISIONS}

As similar to adaptation finance, access to technology remains one of the most significant roadblocks for developing countries to fulfil their ecological sustainable development aspirations. The lack of technology provides an impediment for developing countries' economies from innovating their way towards lower carbon emissions. Furthermore, given their smaller economies of scale compared to developed countries, developing countries remain locked in and rely on advanced economies to continue to develop new technological solutions to mitigate and adapt to a changing climate.

\section{A. UNFCCC and the Kyoto Protocol}

Technology transfer provisions feature prominently within the international legal framework and reflect the important role that environmentally sound technologies

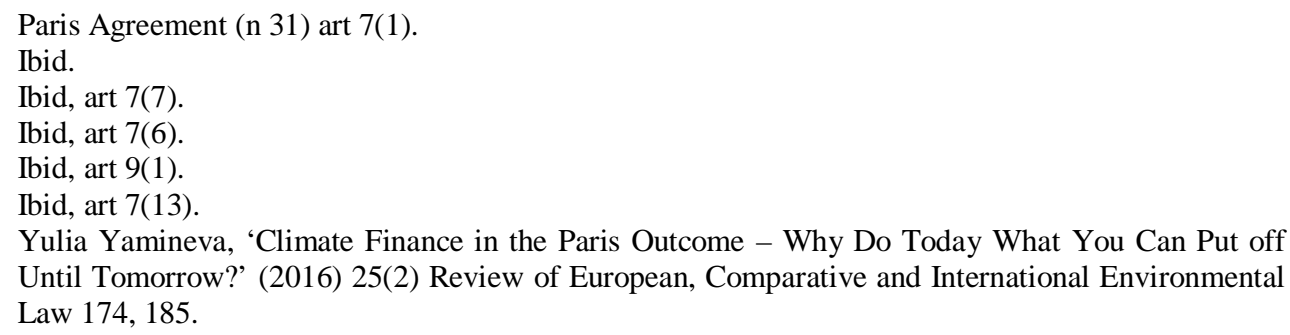


('ESTs') have in combating climate change and promoting sustainable development. ${ }^{83}$ Since its inception in 1992, technology transfer has featured as 'one of the main pillars of the UNFCCC' ${ }^{84}$ The UNFCCC has developed a broad framework for technology transfer that requires all Parties to, inter alia, '[p]romote and cooperate in the development, application and diffusion, including transfer, of technologies, practices and processes that control, reduce or prevent anthropogenic emissions of greenhouse gases'. 85

The UNFCCC aims to facilitate technology transfer to developing countries through articles 4.5 and 4.7 which recognise technology transfer as an essential tool for assisting developing countries to reduce their GHG emissions. ${ }^{86}$ Article 4.5 of the UNFCCC aims to uphold the CBDR principle, which sheds light on the UNFCCC's objective of achieving 'substantive equity, international solidarity and assistance' ${ }^{87}$ Whereas other multilateral environmental agreements (MEAs) use language such as 'encouraging' and 'facilitating' the transfer of ESTs as a form of 'mere diplomatic cosmetics', ${ }^{88}$ the UNFCCC utilises the term 'shall', indicating the intention of the Parties to create binding legal obligations on developed country Parties. ${ }^{89}$ Nevertheless, the Article's use of the term 'as appropriate' appears to suggest that the obligation imposed by Article 4.5 should be implemented in accordance with developed countries' 'international obligations and national legislation'. ${ }^{90}$

The technology transfer commitments within the Convention are further strengthened by Article 4.7. This article has been described as the 'conditionality clause' as it makes implementation of the UNFCCC's commitments from developing countries contingent 'on the effective implementation by developed country parties of their commitments' to transfer technology. ${ }^{91}$ The provision demonstrates the 'political reality' for developing countries in their hesitance to be bound by commitments under the Convention without being provided with the adequate technological support required

83 John H. Barton, Mitigating Climate Change through Technology Transfer: Addressing the Needs of Developing Countries, Energy, Environment and Development Programme (Programme Paper 08/02, Chatham House 2008) 2.

84 Ahmed Abdel-Latif, 'Intellectual Property Rights and the Transfer of Climate Change Technologies: Issues, Challenges, A way Forward' (2015) 15(1) Climate Policy 103, 104.

86 Chen Zhou, 'Can intellectual property rights within climate technology transfer work for the UNFCCC and the Paris Agreement?' (2019) 19(1) International Environmental Agreements: Politics, Law and Economics 107, 109.

87 Ibid.

88 Gaetan Verhoosel, 'Beyond the Unsustainable Rhetoric of Sustainable Development: Transferring Environmentally Sound Technologies' (1998) 11(1) Georgetown International Environmental Law Review 66.

89 Wei Zhuang, Intellectual Property and Climate Change: Interpreting the TRIPS Agreement for Environmentally Sound Technologies (Cambridge University Press 2017) 83.

90 Ibid 85 .

91 Chen Zhou (n 86) 109; UNFCCC (n 28) art 4.7.

Page $\mid 34$ 
to facilitate their sustainable development. ${ }^{92}$ In this vein, failure to transfer technology in accordance with the Convention may result in a material breach, ${ }^{93}$ as the provision can be said to be "essential to the accomplishment of the object or purpose of the treaty' ${ }^{94}$ However, material breach is unlikely to result in sanctions being imposed on developed country Parties, and the provision can therefore be said to 'lack teeth' ${ }^{95}$

Supplementary protocols and agreements are important instruments that operationalise the UNFCCC and assist Parties to implement the Convention. ${ }^{96}$ For example, Articles 3.14 and 10 (c) of the Kyoto Protocol reinforce the importance of technology transfer by committing all Parties to '[c]ooperate in the promotion of effective modalities for the development and diffusion of...environmentally sound technologies'. ${ }^{97}$ Article 11 further highlights the burden sharing nature of technology transfer provisions and in this way reflects that technology transfer forms part of the common but differentiated responsibility of developed country Parties. Overall, the Protocol 'clarifies, strengthens and expands' the scope of the Convention's commitments for the transfer of ESTs. ${ }^{98}$ In an attempt to enhance the implementation of technology transfer, the Protocol also requires 'enabling environments' for the private sector to be created in order to promote and enhance the transfer to ESTs. ${ }^{99}$

\section{B. Paris Agreement}

The Paris Agreement was developed with the primary objective of limiting the rise of global temperature to well below 2 degrees above pre-industrial levels. ${ }^{100}$ In achieving this aim, the Agreement reaffirmed the importance of technology development and transfer in enhancing climate change mitigation and adaptation through the reduction of GHG emissions. ${ }^{101}$ The Parties recognised 'the urgent need to enhance the provision of finance, technology and capacity-building support by developed country Parties' ${ }^{102}$ In acknowledgement of this, Article 10 calls for the strengthening of cooperation between countries with regard to technology development and transfer. Additionally, the Agreement established the 'technology framework' in order to further this goal and provide guidance to the Technology Mechanism established under the UNFCCC. ${ }^{103}$ The technology framework is intended to strengthen the implementation of technology transfer commitments by, inter alia, 'addressing the barriers to the development and

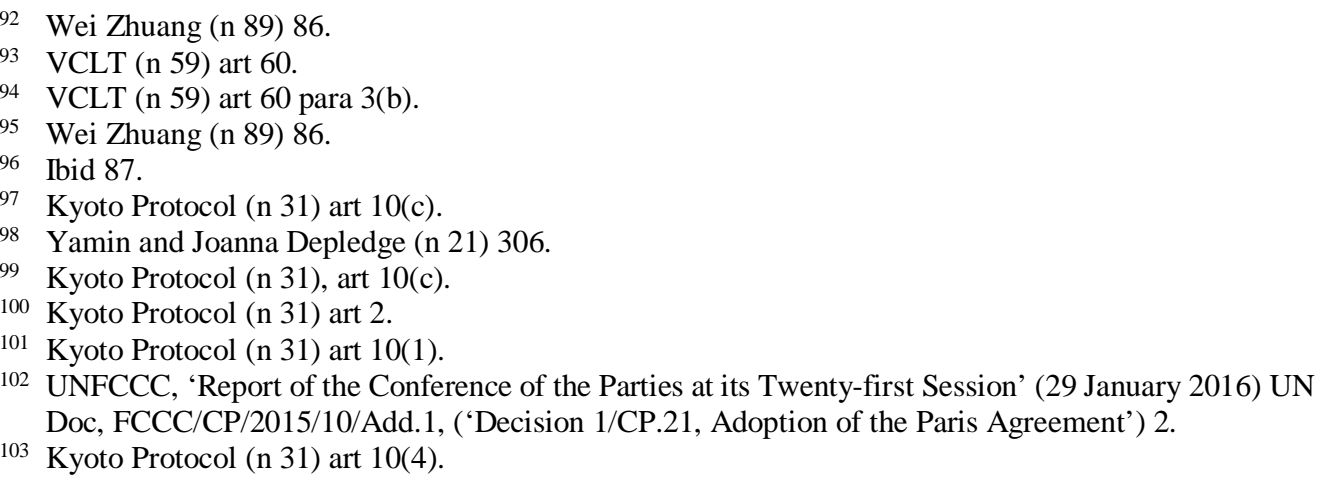


transfer of socially and environmentally sound technologies'. ${ }^{104}$ The Paris Agreement signifies a strengthening and reaffirming of the significant role technology transfer plays in facilitating development, sustainable practices and equitable approaches to tackling global environmental issues such as climate change.

Despite the reaffirmation of technology transfers in the Paris Agreement, effective implementation of technology transfer provisions, and in turn CBDR, remains a challenge. ${ }^{105}$ Rather than relying on designating countries into different tiers both in terms of their capacity to address climate change and their historical contributions, the Paris Agreement relies on Nationally Determined Contributions (NDCs) to outline what steps that countries are taking to address climate change mitigation and adaptation. However, many developing countries are outlining implementation plans which are contingent on external funding from developed countries. With developed countries failing to outline their financial contributions and technology transfers under the Technology Mechanism, there remains no accountability when NDCs are assessed. ${ }^{106}$ As identified by Pauw, developed countries must indicate their financial and technology transfer commitments within their NDCs so that they remain accountable for the commitments that are made towards CBDR.

Effective technology transfer is further impeded by the fact that the actual ownership of the technology, including the "know how" in the production process is in the hands of private ownership and subject to trade secrecy and intellectual property rights, ${ }^{107}$ and therefore also their use is subject to the payment of royalties and user licensing fees, when such technology is diffused on commercial market terms. ${ }^{108}$ It can be seen that whilst technology transfer provisions have been developed in recognition of the CBDR principle and its philosophical bases such as intragenerational equity, the operation of such provisions in practice is impacted by a number of factors that limit treaty implementation and, in turn, hinder the achievement of sustainable development.

Finally, technology transfer in other related international agreements remain ambiguous and provide no clear pathway for realisation. As noted by Neumeyer, 'with such ambiguity built into the system of treaty making, developed countries could on the whole get away without making any specific or substantial commitments' to

104 UNFCCC (n 102) para 67.

105 Wei Zhuang (n 89) 79.

106 Pieter Pauw, 'Subtle Differentiation of Countries' Responsibilities' under the Paris Agreement' (2019) 5(86) Palgrave Communications <https://www.nature.com/articles/s41599-019-0298-6\#citeas> accessed 28 January 2021.

107 Zainal Abidin Sanusi, 'Technology Transfer Under Multilateral Environmental Agreements: Analyzing The Synergies', (Unu-Ias Working Paper No 134, 2005) 2 <http://bei.jcu.cz/Bioeconomy\%20folders/documents/economy/unu-ias-working-paper-no-134technology-transfer-under-multilateral-environmental-agreements-analyzing-the-synergies> Accessed 28 January 2021.

108 Ulrich Hoffmann, 'An Analysis of Effective Operationalization of Provisions on Transfer of Environmentally Sound Technologies to Developing Countries in Multilateral Environmental Agreements' (Paper presented at the 2nd Workshop of the Project on Strengthening Research and Policy-making Capacity on Trade and Environment in Developing Countries, LosBaños, Philippines, 11-13 November 1999) 5.

Page | 36 
provide positive measures in support of compliance and enforcement. ${ }^{109} \mathrm{As}$ a result of this ambiguity, developed countries have abrogated their responsibility to build capacity of developing countries and LDC partners. To date, technology transfer provisions within international environmental law more broadly have remained largely underutilised, and there has been no clear action to translate obligations into tangible outcomes for developing countries.

\section{CONCLUSION}

Sustainable development is a vital part of the current international approach to addressing climate change. However, those countries most vulnerable to the effects of climate changes are also those with the least adaptive capacity. These vulnerable countries are also historically the least responsible for climate change. The CBDR principle is therefore intended to promote fairness and equity in its recognition that while all states bear a responsibility to prevent future environmental harm, developed countries should bear the brunt of this responsibility in consideration of its relative technological and economic strength and historic contributions to environmental degradation. ${ }^{110}$ In this way, climate change adaptation finance and the transfer of ESTs are seen as 'important mechanism[s] giving effect to' the CBDR principle. ${ }^{111}$ However, the effective implementation of this principle is undermined by the tensions that persist between the global North and South as to the responsibility for mitigating environmental harm. ${ }^{112}$ The recognition of responsibility continues to be resisted by some Northern countries that have agreed to compromise and accept differential responsibility obligations on the basis of their 'greater financial and technical capabilities' alone. ${ }^{113}$ This is seen through both the large degree of autonomy that developed countries enjoy in deciding their financial commitments towards climate change adaptation, as well as failing to indicate their technology transfer commitments under the new regime of NDCs under the Paris Agreement.

Although the Paris Agreement hails a new age of identifying specific steps to mitigate and adapt against climate change, in practice CBDR places the onus on developed countries to 'take the lead' in terms of climate change action. While the links between intragenerational equity and sustainable development can be clearly shown, approaches

109 Eric Neumayer, 'Multilateral Environmental Agreements, Trade and Development: Issues and Policy Options Concerning Compliance and Enforcement' (London School of Economics and Political Science 2002) 35 <www.lse.ac.uk/collections/geographyAndEnvironment/whosWho/profiles/ neumayer/pdf/CUTS.pdf> accessed 28 January 2021.

110 Shawkat Alam, 'Sustainable Development versus Green Economy: The Way Forward?' in Shawkat Alam, Sumudu Atapattu, Carmen Gonzalez and Jona Razzaque (eds), International Environmental Law and the Global South (Cambridge University Press 2015) 609, 618.

111 Philippe Sands and Jacqueline Peel (n 17); Rio Declaration on Environment and Development (n 11) principle 7; UNFCCC (n 28) art 3(1).

112 Shawkat Alam (n 110) 617.

113 Ibid 618; Wei Zhuang (n 89) 81. 
to adaptation finance and technology transfer continually fail to reflect this spirit within which international agreements were made. Therefore to remedy this, re-evaluating the rubric of CBDR presents the opportunity for a much-needed link between developed and developing countries in the pursuit of intragenerational equity and sustainable development. 